\title{
NARRATIVAS DE IDOSOS SOBRE AS EXPERIÊNCIAS EM PRÁTICAS CORPORAIS
}

\begin{abstract}
Sabrina Furtunato de Ávila Acadêmica do Curso de Educação Física, Universidade do Extremo Sul Catarinense, sabrinafavila@yahoo.com.br Luana Cademartori Minghelli Acadêmica do Curso de Educação Física, Universidade do Extremo Sul Catarinense, lua_minghelli@yahoo.com.br Amanda Biava Lima Acadêmica do Curso de Educação Física, Universidade do Extremo Sul Catarinense, amanda_biava@hotmail.com Francine Costa de Bom Mestra, Universidade do Extremo Sul Catarinense, costafrancine@hotmail.com

Ana Maria Volpato Doutora, Universidade do Extremo Sul Catarinense, volpatoam@gmail.com Victor Julierme Santos da Conceiçáo Doutor, Universidade Federal de Santa Catarina, victorjulierme@gmail.com
\end{abstract}

\section{RESUMO}

Segundo o Instituto Brasileiro de Geografia e Estatística (IBGE, 2002), no Brasil, estima-se que, em 2025, os idosos atingiráo aproximadamente o número de 30 milhóes de pessoas, o que equivale a $15 \%$ da população brasileira. 
Ao levar em consideração o crescimento da população idosa, torna-se necessário conhecê-la para intervir de forma significativa e pautada em bases que dão suporte a um envolvimento consistente e transformador. No processo de envelhecimento, os elementos que contribuem para a construção da pessoa idosa perpassam os âmbitos biológico, social, psicológico e espiritual. Diante disso, este estudo buscou descrever como as experiências sociais de idosos agem no processo de participação, interiorização e atribuição de importância a práticas corporais. A presente pesquisa é definida como qualitativa do tipo narrativa. Para a coleta dos dados, foi utilizada a entrevista narrativa, a fim de dar voz aos idosos e aprofundar o conhecimento construído a partir de seus relatos. Para selecionar os sujeitos, utilizaram-se critérios de representatividade tipológica, tais como: o tempo de participação no projeto. Dessa forma, foram selecionados quatro idosos que participam do Projeto de Extensão Bola Para Frente, da Universidade do Extremo Sul Catarinense. Diante das experiências sociais narradas pelos idosos, identificamos os elementos que contribuem para a construção da identidade do sujeito, que são contextualizados pelas relaçóes sociais. Nessas relaçóes e na heterogeneidade das práticas sociais, o indivíduo se constrói socialmente, onde suas histórias se ressignificam, dando um sentido maior à vida. As práticas corporais, vivenciadas principalmente na infância e na adolescência, foram significativas, no sentido de que os fatos acontecidos há muitos anos são lembrados pelos idosos como algo marcante, contribuindo para a participação efetiva em práticas corporais realizadas em projetos de exercício físico, como o Bola para Frente.

Palavras-chave: Envelhecimento; Narrativa; Idoso.

\section{REFERÊNCIAS}

BRASIL. Perfil dos idosos responsáveis pelos domicílios no Brasil 2000. Rio de Janeiro: 2002. Disponível em: <http://biblioteca.ibge.gov.br/biblioteca-catalogo?view=detalhes\&id=2929>. Acesso em: 12 fev. 2016. 